\title{
Implantation of peritoneal catheters by laparotomy: nephrologists obtained similar results to general surgeons
}

This article was published in the following Dove Press journal: International Journal of Nephrology and Renovascular Disease 17 October 2014

Number of times this article has been viewed

\section{Cesar A Restrepo Carlos Alberto Buitrago Cielo Holguin}

Division of Nephrology, Department of Health Sciences, Caldas University. Caldas, Colombia
Correspondence: Cesar A Restrepo

Division of Nephrology,

Department of Health Sciences, Caldas University, Calle 25 Nro 48-57, Manizales,

Caldas, Colombia

Tel +576887 I572

Email caugustorv@une.net.co
Purpose: To analyze the complications and costs of minilaparotomies performed by a nephrologist (group A) compared with conventional laparotomies performed by a surgeon (group B) for peritoneal catheter implantation.

Setting: Two university hospitals (Santa Sofia and Caldas) in Manizales, Caldas, Colombia. Methods: The study included stage 5 chronic kidney disease patients, with indication of renal replacement therapy, who were candidates for peritoneal dialysis and gave informed consent for a peritoneal catheter implant. Minilaparotomies were performed by a nephrologist in a minor surgery room under local anesthesia. Conventional laparotomies were performed by a surgeon in an operating room under general anesthesia.

Results: Two nephrologists inserted 157 peritoneal catheters, and seven general surgeons inserted 185 peritoneal catheters. The groups had similar characteristics: the mean age was 55 years, $49.5 \%$ were men, and the primary diagnoses were diabetic nephropathy, hypertensive nephropathy, and unknown etiology. The implant was successful for $98.09 \%$ of group A and $99.46 \%$ of group B. There was no procedure-related mortality. The most frequent complications in the first 30 days postsurgery in group A versus group B, respectively, were: peritonitis $(6.37 \%$ versus $3.78 \%$ ), exit-site infection ( $3.82 \%$ versus $2.16 \%$ ), tunnel infection ( $0 \%$ versus $0.54 \%$ ), catheter entrapment by omentum (1.27\% versus $3.24 \%)$, peritoneal effluent spillover $(1.91 \%$ versus $2.16 \%$ ), draining failure $(4.46 \%$ versus $6.49 \%$ ), hematoma ( $0 \%$ versus $1.08 \%$ ), catheter migration with kinking ( $3.18 \%$ versus $2.70 \%)$, hemoperitoneum $(1.27 \%$ versus $0 \%)$, and hollow viscera accidental puncture $(1.91 \%$ versus $0.54 \%)$. There were no statistically significant differences in the number of complications between groups. In 2013, the cost of a surgeon-implanted peritoneal dialysis catheter in Colombia was US \$366 (666,000 COP), whereas the cost of a nephrologist-implanted catheter was US \$198 (356,725 COP).

Conclusion: Nephrologist-performed minilaparotomies had similar effectiveness to surgeonperformed conventional laparotomies and were cost-effective; however, the nonuse of general anesthesia may be related with hollow viscera puncture during the procedure.

Keywords: catheter implantation, surgical technique, minilaparotomy, complications

\section{Introduction}

There are various techniques to implant peritoneal catheters: conventional laparotomy insertion, laparoscopy, ${ }^{1,2}$ fluoroscopic guide, ${ }^{3}$ and percutaneous insertion by the Seldinger technique. ${ }^{4}$ Laparotomy and laparoscopic techniques are often used in the UK, where $71.7 \%$ of peritoneal catheters are implanted by surgeons; by 2006 , similar statistics were reported in the USA. ${ }^{5,6}$ The main advantages of these techniques are their simplicity and the use of non-advanced instruments. However, the costs are high, hospitalization is necessary - often for more than 1 day, ${ }^{7}$ a general surgeon and 
operating room is required, the surgical time is longer, an anesthesiologist is needed for general anesthesia, and there is a longer time between the decision and procedure (during which time the patient may decline the surgery).

The percutaneous technique is usually performed by nephrologists and radiologists. ${ }^{8-10}$ It's advantages include not requiring general anesthesia and thus a shorter interval between the decision and the procedure, less postsurgical pain, faster recuperation and postsurgical ambulation, and a lower monetary cost, which has increased the penetration of peritoneal dialysis programs. ${ }^{11,12}$ However, the blind nature of the procedure means there is risk for hollow viscera puncture and bleeding in the abdominal wall vessels; therefore, it is contraindicated in patients with previous abdominal surgery and in patients that are obese.

Laparotomy with a minimum opening of the peritoneum (minilaparotomy) enables catheter implantation with direct visualization of the peritoneum and the ability to place the catheter in the left iliac fossa in a more secure and effective way. This study presents the authors' experience with this technique and analyzes the complications and costs of the procedure compared with conventional laparotomy.

\section{Patients, materials, and methods}

The study included stage five chronic kidney disease patients who were candidates for peritoneal dialysis and gave informed consent for a peritoneal catheter implant.
The procedures were performed in two university hospitals (Santa Sofia and de Caldas) in Manizales, Colombia.

Minilaparotomies were performed by a nephrologist in a minor surgery room under local anesthesia, without sedation and without an anesthesiologist.

The protocol of medication for the procedure included $1 \mathrm{~g}$ cefalotin intravenously 30 minutes before the procedure and, for postsurgical pain, one ampule of dipyrone intravenously 30 minutes prior to surgery completion.

Two nephrologists implanted the peritoneal catheters. Before the procedure, all the patients emptied their bladder. The technique was performed as follows. A left paramedian horizontal incision was made at the midpoint of an imaginary line between the umbilicus and the anterior superior iliac crest. The subcutaneous cellular tissue was bluntly dissected to expose the anterior fascia of the abdominal rectus. A vertical incision on the fascia was made and the muscle was bluntly dissected to expose the posterior fascia. The posterior fascia was elevated with a Kelly clamp (Figure 1). A continuous purse-string suture was made around the clamp and a tiny incision was made in the fascia (no more than $1.5 \mathrm{~cm}$ ) to expose the peritoneum, and a long and rigid stiletto was inserted into the catheter (Figure 2). The hardened catheter was inserted into the tiny hollow and directed deeply to the left iliac fossa. The stiletto was pulled, releasing the catheter, and secured with a purse-string suture. The internal cuff was positioned external to the posterior fascia. Then, $500 \mathrm{~mL}$ of
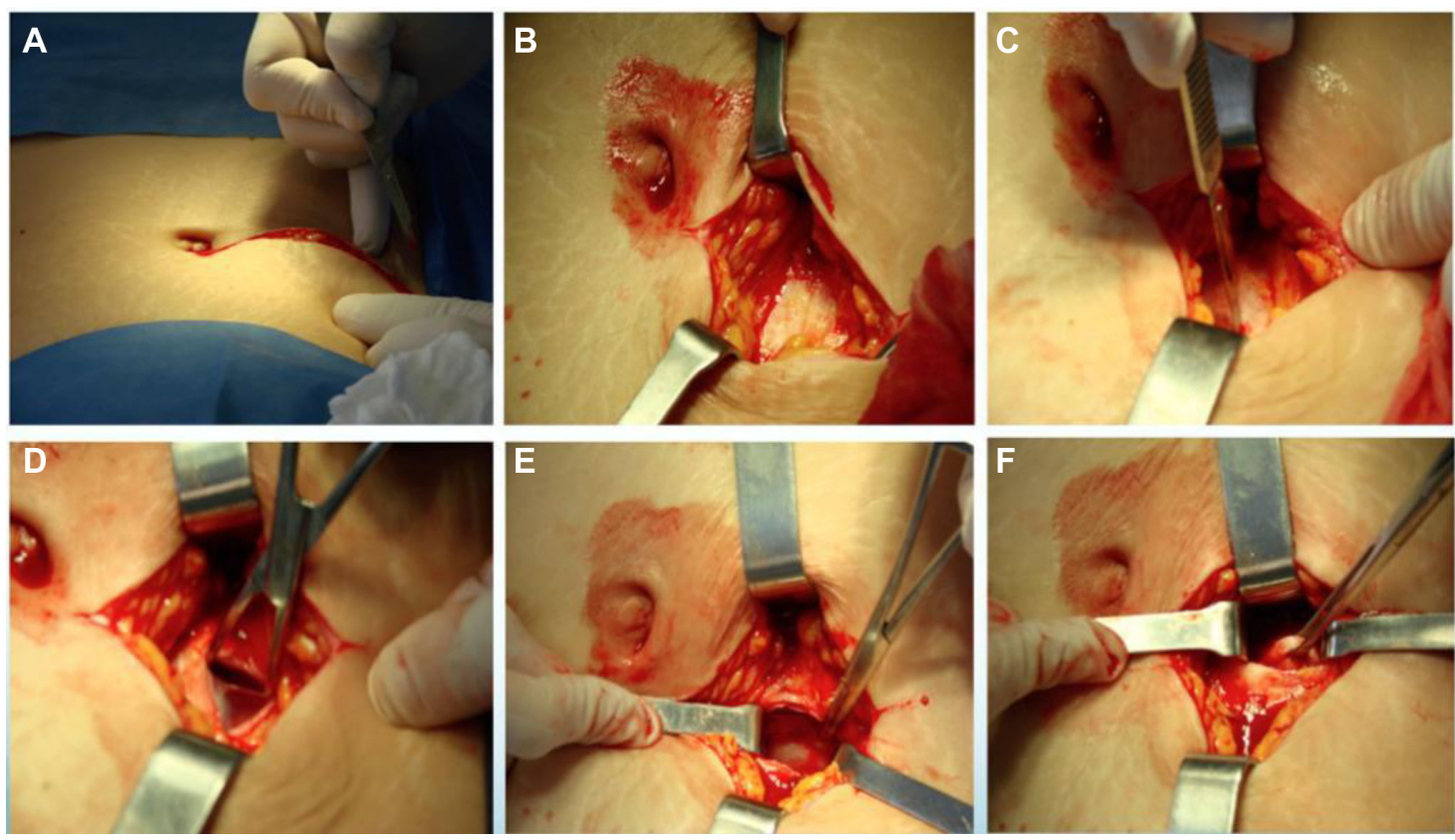

Figure I Insertion of a peritoneal catheter using the minilaparotomy technique.

Notes: The skin and cellular tissue were dissected to expose the posterior fascia, which was then elevated with a Kelly clamp. (A) Left paramedian incision; (B) exposing the anterior fascia; (C) vertical incision on the fascia; (D) rectus muscle dissection; (E) exposing the posterior fascia; (F) elevation of posterior fascia. 

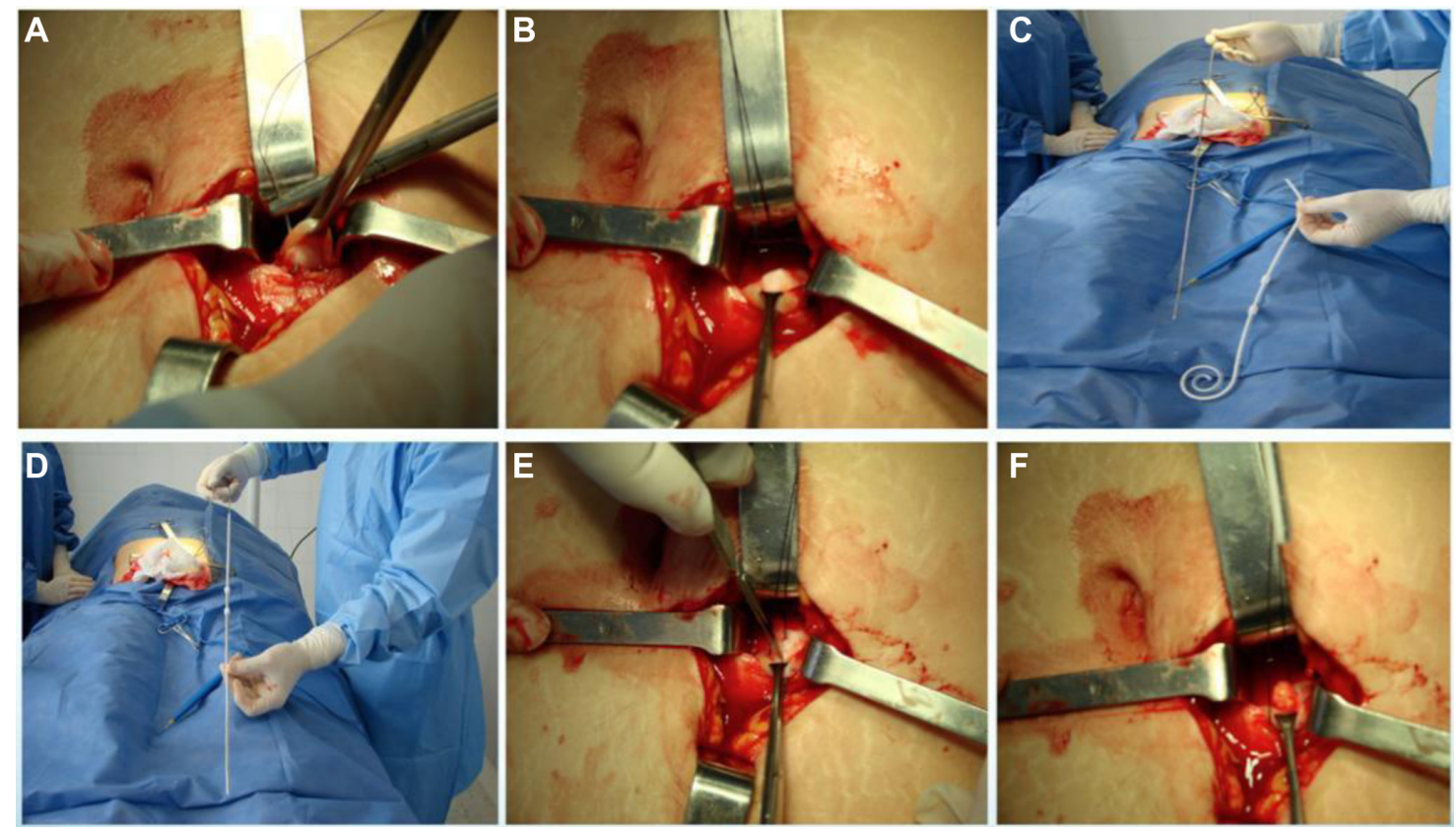

Figure 2 A continuous purse-string suture was made around the Kelly clamp.

Notes: A stiletto was inserted into the catheter and a tiny incision was made in the fascia to expose the peritoneum. (A, B) Purse-string suture in posterior fascia; (C, D) stiffen the catheter with a stiletto; (E) tiny incision in posterior fascia; (F) exposing the peritoneum.

isotonic saline was infused into the cavity to probe the patency of the catheter, and the correct effluence was checked (Figure 3). If a good flow was present in both directions, the anterior fascia was closed with a crossed continuous suture; the internal cuff was left in the rectus muscle. A little incision was made in the right supraumbilical area, a subcutaneous tunnel was formed, and the catheter was directed to an external orifice, calculating that the external cuff would stay $5-10 \mathrm{~cm}$ of the external orifice. Finally, the skin and cellular subcutaneous tissue were sutured (Figure 4).
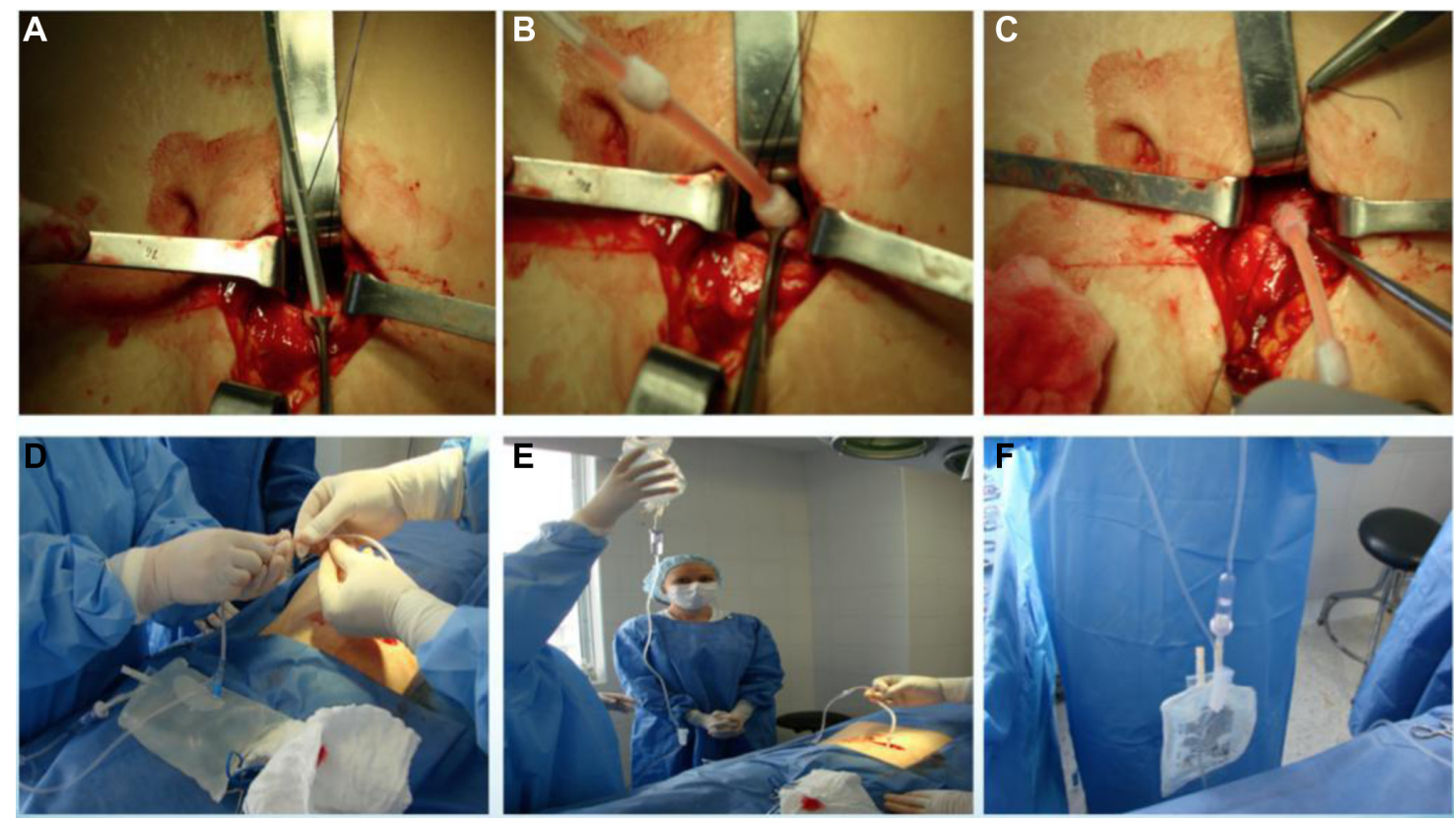

Figure 3 The hardened catheter was inserted deep into the tiny hollow of the left iliac fossa and secured with a purse-string suture.

Notes: To probe the patency of the catheter, $500 \mathrm{~mL}$ of normal saline was infused into the cavity. (A) Introduction of hardened catheter; (B) removal of stiletto; (C) closure of posterior fascia; (D-F) infusion of saline, and catheter patency test. 

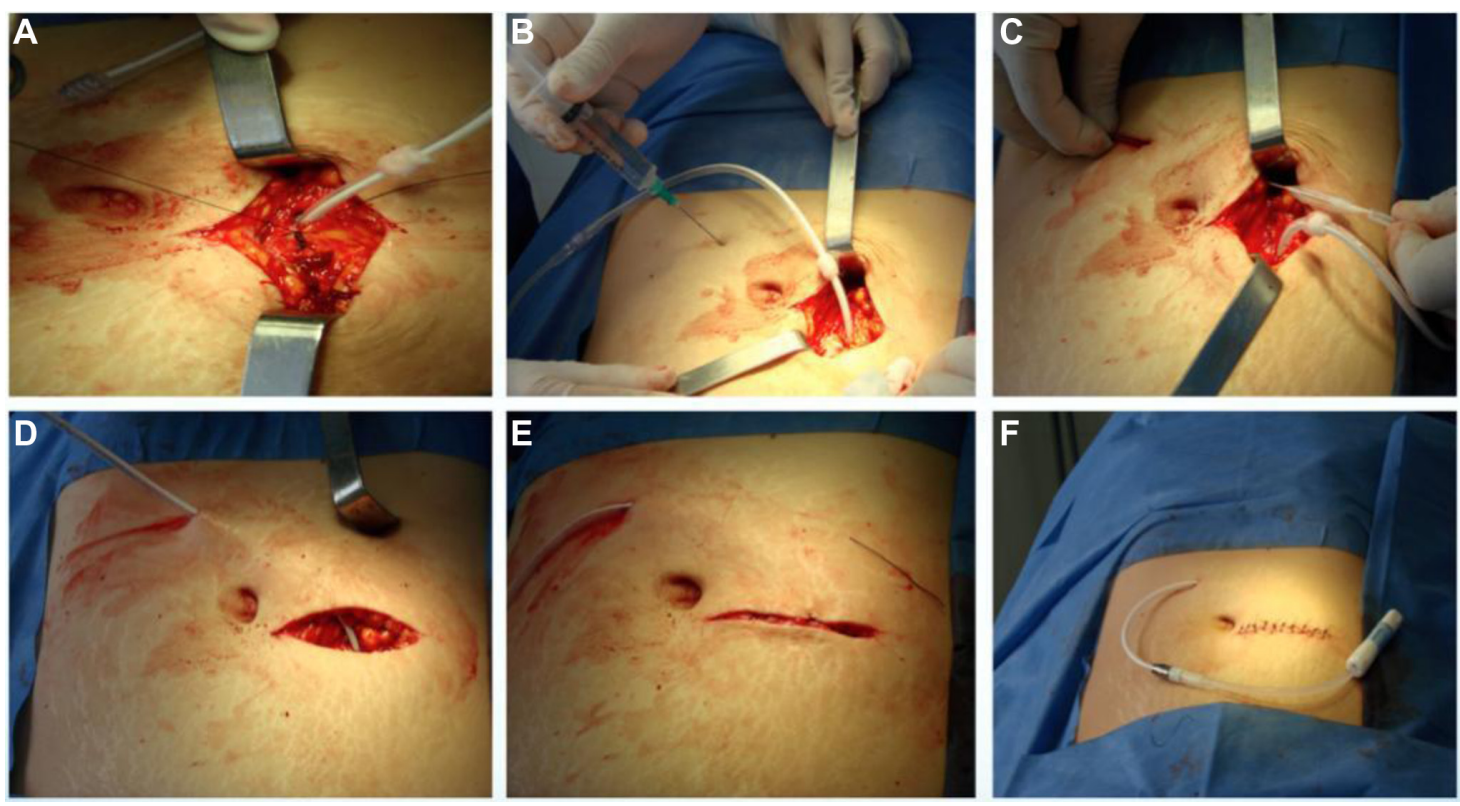

Figure 4 Closure of the anterior fascia.

Notes: The internal cuff was left in the rectus muscle. A subcutaneous tunnel was made and the catheter was directed to an external orifice. The skin and subcutaneous tissue were sutured. (A) Closure of anterior fascia; (B) anesthesia and incision for exit site; (C, D) subcutaneous tunneling of catheter; (E, F) skin and subcutaneous tissue sutured.

Conventional laparotomies, the technique of which has been widely described, ${ }^{1,9}$ were performed by a surgeon in an operating room under general anesthesia, with the participation of an anesthesiologist.

Minilaparotomy insertion was declined if the patient had previous surgery other than an appendectomy, uncomplicated cholecystectomy, or cesarean and if the patient had hemorrhagic diathesis, a uncorrected abdominal wall hernia, or morbid obesity.

In both laparotomy techniques, Tenckhoff two-cuff catheters were implanted. After surgery, the peritoneal cavity was washed weekly with $500 \mathrm{~mL}$ of $1.5 \%$ peritoneal solution until therapy began 2 weeks later. The catheter exit site was permanently covered for good cicatrization; every week a trained nurse did a sterile lavage and applied gentamicin ointment for prophylaxis of bacterial infection.

Global procedure costs, patient characteristics (age, sex, etiology of chronic kidney disease); procedure success, procedure-related mortality, and complications in the first 30 days postsurgery (peritonitis, exit-site infection, tunnel infection, omentum entrapment, surgical wound or exit-site liquid leakage, catheter malfunctioning, drainage failure, surgical wound hematoma, catheter migration with kinking, hemoperitoneum, hollow viscera accidental puncture, and catheter repositioning or change) were the variables analyzed.

The choice to perform either procedure was simply based on the time availability of the nephrologists or general surgeons, although patients with previous abdominal surgery (except for appendectomy, uncomplicated cholecystectomy, or cesarean), refractory peritonitis prior to antimicrobial therapy that required removal of the peritoneal catheter, and morbid obesity had surgery performed by a general surgeon with the conventional technique. Patients who, for any reason, required laparoscopic catheter placement for peritoneal dialysis or had a previous omentectomy were not included in this study.

The cost analysis included nurse, surgeon, anesthesiologist, and nephrologist fees in addition to surgical room and material costs.

For statistical analysis, minilaparotomy patients were categorized as group A and conventional technique patients were categorized as group B. Complications and cost comparisons were analyzed by group comparison. For quantitative variables, means and standard deviations were calculated. Quantitative data were analyzed using the Student's $t$-test, and qualitative data were analyzed using the Pearson's chisquare test. SPSS version 15.0, licensed to Caldas University (Manizales, Colombia), was used for all analyses.

\section{Results}

Over a 17-year period, from 1996-2013, 342 patients underwent peritoneal catheter insertion: 157 patients by minilaparotomy performed by two nephrologists and 185 patients by conventional technique performed by seven general surgeons. Patients' age, sex, and etiology of chronic kidney disease are presented in Table 1; there were no significant differences between group A and group B. 
Table I Comparative variables

\begin{tabular}{|c|c|c|c|c|}
\hline & \multicolumn{2}{|c|}{$\begin{array}{l}\text { Group A: } \\
\text { nephrologists }\end{array}$} & \multicolumn{2}{|c|}{$\begin{array}{l}\text { Group B: } \\
\text { general } \\
\text { surgeons }\end{array}$} \\
\hline & $n$ & $\%$ & n & $\%$ \\
\hline Total catheter insertions & 157 & 100 & 185 & 100 \\
\hline Male & 79 & 50.32 & 92 & 49.73 \\
\hline Female & 78 & 49.68 & 93 & 50.27 \\
\hline Age (mean) & \multicolumn{2}{|c|}{57 years } & \multicolumn{2}{|c|}{53 years } \\
\hline \multicolumn{5}{|l|}{ Renal disease etiology } \\
\hline Hypertension & 58 & 36.94 & 31 & 16.76 \\
\hline Diabetes & 64 & 40.76 & 62 & 33.51 \\
\hline Unknown & 16 & 10.19 & 56 & 30.27 \\
\hline Hereditary disease & 1 & 0.64 & 1 & 0.54 \\
\hline Chronic glomerulonephritis & 8 & 5.1 & 10 & 5.41 \\
\hline Secondary glomerulopathy & 2 & 1.27 & 0 & 0.00 \\
\hline Obstructive nephropathy & 8 & 5.1 & 17 & 9.19 \\
\hline Chronic interstitial nephritis & & & 8 & 4.32 \\
\hline \multicolumn{5}{|l|}{ Successful insertion } \\
\hline Yes & 154 & 98.09 & 184 & 99.46 \\
\hline No & 3 & 1.91 & 1 & 0.54 \\
\hline \multicolumn{5}{|l|}{ Previous surgery } \\
\hline No & $|5|$ & 96.18 & 158 & 85.41 \\
\hline Yes & 6 & 3.82 & 27 & 14.59 \\
\hline \multicolumn{5}{|l|}{ Hernia } \\
\hline Yes & 6 & 3.82 & 10 & 5.41 \\
\hline No & $|5|$ & 96.16 & 175 & 94.59 \\
\hline \multicolumn{5}{|l|}{ Previous hernia correction } \\
\hline Yes & 6 & 3.82 & 10 & $5.4 I$ \\
\hline
\end{tabular}

Six patients (3.82\%) in group A and 27 (14.59\%) in group B underwent previous surgery that didn't contraindicate the procedure. Prior to implantation, $3.82 \%$ patients in group A and $5.41 \%$ in group B underwent abdominal wall hernia correction. Implantation was successful in $98.09 \%$ (154 patients) of group A and $99.46 \%$ (184 patients) of group B (Table 1). Three (1.91\%) patients in group A suffered hollow viscera puncture (one in the stomach, one in the small intestine, and one in the descending colon) and one $(0.54 \%)$ patient in

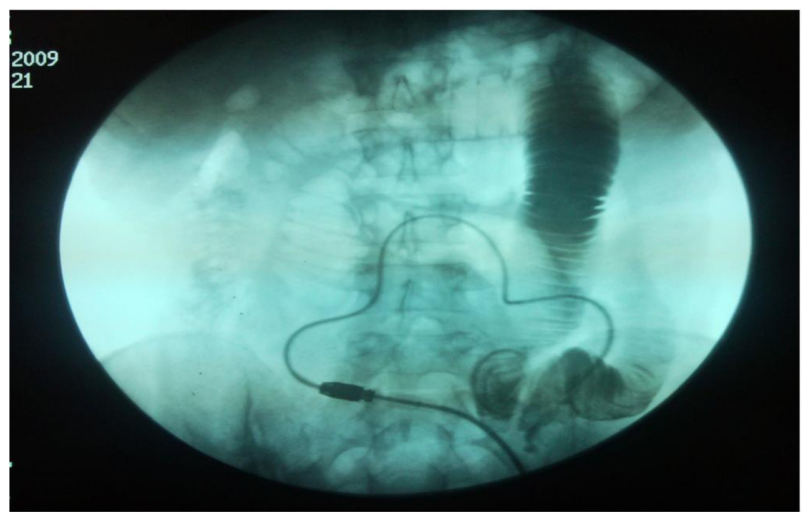

Figure 5 Image of an intestinal perforation.

Note: The radiocontrast agent was infused by the peritoneal catheter. group B (in the bladder) (Figure 5). Hollow viscera puncture was treated with a nasogastric tube and digestive resting for 8 days and antibiotic prophylaxis for both Gram-positive and Gram-negative bacteria. The implantation procedure was suspended or the catheter retired with suspicion or radiologic confirmation. The patients with hollow viscera puncture underwent surgeon-performed peritoneal catheter implantation 2 months later, which were all successful and peritoneal dialysis was initiated without problems.

Drainage failure was more frequent in group B; the main cause was catheter kinking and entrapment by omentum or constriction bands. Other causes included abdominal wall hernia, surgical wound, or exit-site peritoneal fluid spillover and peritoneum-genital or peritoneum-pleural fistulae. Laparoscopic repositioning was used to treat kinking and omentectomy or re-implantation were the therapeutic strategies for omentum entrapment (Table 2).

Peritoneal dialysis ceasing within 30 days was a successful treatment for peritoneal fluid leakage; after 30 days, dialysis was restarted with half-volume dwells. For peritoneum-genital fistula, surgical treatment was indicated; for peritoneum-pleural fistula, tetracycline pleurodesis without catheter retirement was used. A few catheters were removed without posterior replacement: one patient in group A for

Table 2 Procedure-related complications

\begin{tabular}{|c|c|c|c|c|}
\hline & \multicolumn{2}{|c|}{$\begin{array}{l}\text { Group A: } \\
\text { nephrologists }\end{array}$} & \multicolumn{2}{|c|}{$\begin{array}{l}\text { Group B: } \\
\text { general } \\
\text { surgeons }\end{array}$} \\
\hline & $\mathbf{n}$ & $\%$ & $\mathbf{n}$ & $\%$ \\
\hline \multicolumn{5}{|l|}{ Complications } \\
\hline After first lavage hernia & I & 0.64 & I & 0.54 \\
\hline Kinking & 5 & 3.18 & 5 & 2.70 \\
\hline Surgical wound liquid effusion & I & 0.64 & I & 0.54 \\
\hline Exit-site liquid effusion & 2 & 1.27 & 3 & 1.62 \\
\hline Drainage failure & 7 & 4.46 & 12 & 6.49 \\
\hline Peritoneum-genital fistula & I & 0.64 & I & 0.54 \\
\hline Peritoneum-pleural fistula & I & 0.64 & 0 & 0.00 \\
\hline Hemoperitoneum & 2 & 1.27 & 0 & 0.00 \\
\hline Exit-site infection & 6 & 3.82 & 4 & 2.16 \\
\hline Bacterial peritonitis & 10 & 6.37 & 7 & 3.78 \\
\hline Surgical wound hematoma & 0 & 0.00 & 2 & 1.08 \\
\hline Tunnel infection & 0 & 0.00 & I & 0.54 \\
\hline Gastric or intestinal puncture & 3 & 1.91 & 0 & 0.00 \\
\hline Bladder puncture & 0 & 0.00 & I & 0.54 \\
\hline Omentum or bands trapping & 2 & 1.27 & 6 & 3.24 \\
\hline None & 116 & 73.89 & $|4|$ & 76.22 \\
\hline \multicolumn{5}{|l|}{ Complication treatment } \\
\hline Re-implantation & 2 & 1.27 & 8 & 3.24 \\
\hline Re-accommodation catheter & 5 & 3.18 & 5 & 2.70 \\
\hline Retirement of catheter & I & 0.64 & 2 & 1.08 \\
\hline Reference period & \multicolumn{2}{|c|}{ February 1996- } & \multicolumn{2}{|c|}{$\begin{array}{l}\text { October } 1999 \\
\text { June } 2013\end{array}$} \\
\hline
\end{tabular}


refractory peritoneum-pleural fistula and two patients in group B - one for fungal peritonitis and another for ultrafiltration failure, who was migrated to hemodialysis.

Sixteen (10.19\%) patients in group A had infectious complications: ten with bacterial peritonitis (6.37\%) and six with exit-site infection (3.82\%). Twelve (6.48\%) patients in group B had infectious complications: seven with bacterial peritonitis (3.78\%), four with exit-site infection (2.16\%), and one with tunnel infection $(0.54 \%)$. There were no statistically significant differences between the groups. The pathogens are depicted in Table 3. The treatment for peritonitis was done according to the authors' protocol with intraperitoneal antibiotics in a once-daily dose ${ }^{13}$ in one case it was necessary to remove the catheter for fungal peritonitis.

Hemoperitoneum and hematoma were infrequent complications.

By 2013, a general surgeon-performed procedure cost US $\$ 366$ (666,000 COP) and a nephrologist-performed procedure cost US \$198 dollars (356,735 COP).

There were no statistically significant differences between group A and group B in the complications analysis $(P>0.05$; Tables 4 and 5).

\section{Discussion}

The percutaneous implantation technique of peritoneal catheters, usually practiced by nephrologists and radiologists, has the advantages ${ }^{8-10}$ of not requiring general anesthesia and

Table 3 Germ list

\begin{tabular}{|c|c|c|}
\hline Complication & Cases (n) & Germ \\
\hline \multicolumn{3}{|c|}{ Group A: nephrologists' isolated germ list } \\
\hline Bacterial peritonitis & 2 & Unidentified \\
\hline Bacterial peritonitis & I & Enterococcus faecalis \\
\hline Bacterial peritonitis & 2 & Staphylococcus aureus \\
\hline Bacterial peritonitis & I & Escherichia coli \\
\hline Bacterial peritonitis & I & Klebsiella oxytoca \\
\hline Bacterial peritonitis & I & Pseudomonas aeruginosa \\
\hline Bacterial peritonitis & I & Staphylococcus epidermidis \\
\hline Bacterial peritonitis & I & Acinetobacter Iwoffii \\
\hline Exit-site infection & I & Unidentified \\
\hline Exit-site infection & I & Proteus mirabilis \\
\hline Exit-site infection & 3 & S. aureus \\
\hline Exit-site infection & I & S. epidermidis \\
\hline \multicolumn{3}{|c|}{ Group B: general surgeons' germ list } \\
\hline Bacterial peritonitis & 4 & Unidentified \\
\hline Bacterial peritonitis & I & Enterobacter agglomerans \\
\hline Bacterial peritonitis & I & Candida parapsilosis \\
\hline Bacterial peritonitis & I & Klebsiella pneumoniae \\
\hline Exit-site infection & 2 & Unidentified \\
\hline Exit-site infection & I & S. aureus \\
\hline Exit-site infection & I & Serratia marcescens \\
\hline Tunnel infection & I & Unidentified \\
\hline
\end{tabular}

Table 4 Statistical analysis: contingency table

\begin{tabular}{lllll}
\hline & Complication & No & Yes & Total \\
\cline { 2 - 4 } & Frequency & & & \\
\hline Surgeon & $\mathrm{n}$ & $14 \mathrm{I}$ & 44 & 185 \\
& $\%$ & 76.2 & 23.8 & 100 \\
Nephrologist & $\mathrm{n}$ & 116 & $4 \mathrm{I}$ & 157 \\
& $\%$ & 73.9 & 26.1 & 100 \\
Total & $\mathrm{n}$ & 257 & 85 & 342 \\
& $\%$ & 75.1 & 24.9 & 100 \\
\hline
\end{tabular}

thus no long wait for surgery room, less postoperative pain, and faster recovery and postsurgical ambulation. In addition, it has a lower monetary cost, which has increased the penetration of peritoneal dialysis programs. ${ }^{11,12}$

However, in this technique, only skin and cellular subcutaneous tissues are dissected to expose the anterior fascia, a blind puncture is made to reach the peritoneal cavity usually with a 16-gauge needle, and, posteriorly, a guide wire is inserted through the needle. The needle is taken out, leaving the guide wire in situ to advance dilatators and other devices for catheter implantation in the cavity. Due to this procedure being of a blind nature, there is risk for hollow viscera puncture, peritoneal infection and bleeding in the abdominal wall blood vessels. In addition, this technique is contraindicated in obese patients and those who have had previous abdominal surgery.

In this paper, the incidence of procedure-related complications was compared between nephrologist-implanted and surgeon-implanted catheters by two similar surgical techniques and in different scenarios - under local or general anesthesia. Although a higher incidence of hemoperitoneum, peritonitis, and hollow viscera puncture was reported when nephrologists performed the procedure, statistical analysis showed no significant differences. It is important to note that the incidence of hollow viscera puncture occurred within the first 5 years of first performing the procedure, which is most likely related to the learning curve. The results obtained by nephrologists are without a doubt also influenced by patient selection, because those with previous abdominal surgery (except for appendectomy, uncomplicated cholecystectomy, or cesarean), refractory peritonitis prior to antimicrobial therapy that required removal of peritoneal catheter, and morbid obesity were always operated on by general surgeons.

There are few papers comparing peritoneal catheter insertion techniques. Zappacosta et al studied the implantation of 113 catheters: 82 by the Seldinger technique and 31 by laparotomy in chronic kidney disease and some acute kidney injury patients. The results were similar in both groups, but there were two hollow viscera perforations and a 
Table 5 Statistical analysis: chi-square tests

\begin{tabular}{llllll}
\hline & Value & $\begin{array}{l}\text { Degrees of } \\
\text { freedom }\end{array}$ & $\begin{array}{l}\text { Significance } \\
\text { level asymptotic } \\
\text { (bilateral) }\end{array}$ & $\begin{array}{l}\text { Significance } \\
\text { level exact } \\
\text { (bilateral) }\end{array}$ & $\begin{array}{l}\text { Significance } \\
\text { level exact } \\
\text { (unilateral) }\end{array}$ \\
\hline Pearson's chi-square & 0.247 & $\mathrm{I}$ & 0.619 & \\
Yates' correction & 0.138 & $\mathrm{I}$ & 0.710 & \\
Odds ratio & 0.247 & $\mathrm{I}$ & 0.619 & 0.707 & 0.355 \\
Fisher's exact test & 342 & & & & \\
Valid cases $(\mathrm{n})$ & & & & \\
\hline
\end{tabular}

cystic puncture in an autosomal dominant polycystic kidney disease patient undergoing the percutaneous technique. ${ }^{14}$ In Turkey, Ozener et al compared 133 nephrologist-implanted peritoneal catheters by percutaneous technique versus 82 by conventional surgical technique. No difference between these techniques was detected in the incidence of surgical complications, although peritonitis was presented in $16 \%$ of patients in the percutaneous technique group and there was greater incidence of later peritoneal liquid leakage. ${ }^{9}$

Mellote et al inserted 230 peritoneal catheters: 50 by percutaneous technique and 180 by conventional surgical technique. They detected a higher incidence of surgical complications in the percutaneous technique group. ${ }^{15}$

In a recent study, Medani et al compared the implantation of catheters inserted by the percutaneous technique with local anesthesia $(n=151)$ versus open surgery with general anesthesia ( $\mathrm{n}=162)$. The results showed that there was more peritoneal liquid leakage (20.5\% versus $6.8 \%)$ and exit-site infections by the percutaneous technique, and a major rate of peritonitis and abdominal wall hernia was found in the surgical group. There were no differences in primary patency failure or ultrafiltration failure. The technique survival at 3 months was significantly better in the percutaneous technique group. ${ }^{16}$

In Brazil, de Morales et al performed a multicenter analysis that compared 163 peritoneal catheters implanted by nephrologists ( 23 by laparotomy, 125 by percutaneous technique, and eight by peritoneoscopy) with 573 procedures performed by general surgeons (mostly by laparotomy). No significant differences were detected in the appearance of mechanical or infectious complications. Interestingly, in this publication, laparotomy was described as a technique practiced by nephrologists for the implantation of peritoneal catheters. ${ }^{17}$

Also in Brazil, Chula et al compared the results of nephrologist-implanted peritoneal catheters by percutaneous and laparoscopic techniques with general surgeon-performed laparotomy. In 121 procedures, no significant difference was detected in the mechanical or infectious complications. ${ }^{18}$
In regard to the procedural costs of both techniques, Sampathkumar et al studied a sample of 46 catheter implantations: 25 by the percutaneous technique and 21 by open surgery. They stressed the smaller size of the surgical wound, shorter hospitalization, early initiation of peritoneal exchanges, and cost reduction as benefits of the percutaneous technique; however, higher intestinal puncture risk and fluid leakage was reported. ${ }^{19}$

In a recent series, Salonen and Saha also analyzed the costs of peritoneal catheter implantation in inpatients versus outpatients using a conventional open minilaparotomy technique in all patients (usually under a spinal anesthetic). They found that outpatient peritoneal catheter implantation significantly reduced procedural costs with similar outcomes to an inpatient procedure. ${ }^{20}$

When compared with the complications of the percutaneous technique and general surgeon-performed laparotomy reported by other authors, the authors' technique showed similar results and lower cost. Like the percutaneous technique, the advantage of the authors' technique over conventional laparotomy is that it does not require general anesthesia and can be performed in a minor surgery room, which shortens the time between the decision of the patient and catheter implantation. However, it is superior to the percutaneous technique as it provides a lower risk of puncturing abdominal wall vessels (and in this case it is easily solved), dilators and "pull-apart" introducers are not necessary, and it gives the warranty of an intraperitoneal and left iliac fossa-located catheter. The disadvantages of the authors' technique include longer surgical time (10-15 more minutes) and more surgical devices (bigger dividers and different surgical clamps and sutures).

The authors suggest that nephrologists should assume a more interventionist attitude; this procedure will give them more postsurgical confidence once it is implemented. The limitation that occurs in some countries, ie, a surgeon is required to practice laparotomies, could prevent the spread of this technique among nephrologists. However, if similar results between the two techniques can be attained in a 
suitable training center as reported here, it is possible to popularize the nephrologist-performed procedure.

\section{Disclosure}

The authors report no conflicts of interest in this work.

\section{References}

1. Soontrapornchai P, Simapatanapong T. Comparison of open and laparoscopic secure placement of peritoneal dialysis catheters. Surg Endosc. 2005;19(1):137-139.

2. Santarelli S, Zeiler M, Monteburini T, et al. Videolaparoscopic catheter placement reduces contraindications to peritoneal dialysis. Perit Dial Int. 2013;33(4):372-378.

3. Voss D, Hawkins S, Poole G, Marshall M. Radiological versus surgical implantation of first catheter for peritoneal dialysis: a randomized noninferiority trial. Nephrol Dial Transplant. 2012;27(11):4196-4204.

4. Al-Hwiesh AK. Percutaneous peritoneal dialysis catheter insertion by a nephrologist: a new, simple, and safe technique. Perit Dial Int. 2014;34(2):204-211.

5. Wilkie M, Wild J. Peritoneal dialysis access - results from a UK survey. Perit Dial Int. 2009;29(3):355-357.

6. Negoi D, Prowant BF, Twardowski ZJ. Current trends in the use of peritoneal dialysis catheters. Adv Perit Dial. 2006;22:147-152.

7. Agulnik M, Hirsch DJ. Resource utilization for peritoneal catheter placement. ASAIO J. 2001;47(1):97-98.

8. Allon M, Soucie JM, Macon EJ. Complications with permanent peritoneal dialysis catheters: experience with 154 percutanously placed catheters. Nephron. 1988;48(1):8-11.

9. Ozener C, Bihorac A, Akoglu E. Technical survival of CAPD catheters: comparison between percutaneous and conventional surgical placement techniques. Nephrol Dial Transplant. 2001;16(9):1893-1899.

10. Aksu N, Yavascan O, Anil M, Kara OD, Erdogan H, Bal A. A 10-year single-center experience in children on chronic peritoneal dialysis significance of percutaneous placement of peritoneal dialysis catheters. Nephrol Dial Transplant. 2007;22:2045-2051.
11. Asif A, Pflederer TA, Viera CF, Diego J, Roth D, Agarwal A. Does catheter insertion by nephrologist improve peritoneal dialysis utilization? A multicenter analysis. Semin Dial. 2005;18(2):157-160.

12. Goh BL, Ganeshadeva YM, Chew SE, Dalami MS. Does peritoneal dialysis catheter insertion by interventional nephrologists enhance peritoneal dialysis penetration? Semin Dial. 2008;21(6):561-566.

13. Restrepo CA. [Treatment of bacterial peritonitis with once-daily dose of intraperitoneally antibiotics]. Acta Med Colomb. 2006;31(3):97-103. Spanish.

14. Zappacosta AR, Perras ST, Closkey GM. Seldinger technique for Tenckhoff catheter placement. ASAIO Trans. 1991;37(1):13-15.

15. Mellote GJ, Ho CA, Morgan SH, Bending MR, Eisinger AJ. Peritoneal dialysis catheters: a comparison between percutaneous and conventional surgical placement techniques. Nephrol Dial Transplant. 1993;8(7): 626-630.

16. Medani S, Shantier M, Hussein W, Wall C, Mellote G. A comparative analysis of percutaneous and open surgical techniques for catheter placement. Perit Dial Int. 2012;32(6):628-635.

17. de Morales TP, Campos RP, de Alcantara MT, et al. Similar outcomes of catheters implanted by nephrologist and surgeons: analysis of the Brazilian peritoneal dialysis multicentric study. Semin Dial. 2012;25(5): 565-568.

18. Chula DC, Campos RP, de Alcantara MT, Riella MC, do Nascimento MM. Percutaneous and surgical insertion of peritoneal catheter in patients starting in chronic dialysis therapy: a comparative study. Semin Dial. 2014;27(3):E32-E37.

19. Sampathkumar K, Mahaldar AR, Sooraj YS, Ramkrishnan M, Ajeshkumar, Ravichandran R. Percutaneous CAPD catheter insertion by a nephrologist versus surgical placement: a comparative study. Indian J Nephrol. 2008;18(1):5-8.

20. Salonen TE, Saha H. Structured outpatient peritoneal dialysis catheter insertion is safe and cost-saving. Perit Dial Int. Epub July 1, 2013.

\section{Publish your work in this journal}

The International Journal of Nephrology and Renovascular Disease is an international, peer-reviewed open-access journal focusing on the pathophysiology of the kidney and vascular supply. Epidemiology, screening, diagnosis, and treatment interventions are covered as well as basic science, biochemical and immunological studies. The journal welcomes original research, clinical studies, reviews \& evaluations, expert opinion and commentary, case reports and extended reports. The manuscript management system is completely online and includes a very quick and fair peerreview system, which is all easy to use. Visit http://www.dovepress.com/ testimonials.php to read real quotes from published authors. 